\title{
Signal transduction in pancreatic stellate cells
}

\author{
Atsushi Masamune $\cdot$ Tooru Shimosegawa
}

Received: 17 November 2008/ Accepted: 18 November 2008/Published online: 7 March 2009

(C) Springer 2009

\begin{abstract}
Pancreatic fibrosis is a characteristic feature of chronic pancreatitis and of desmoplastic reaction associated with pancreatic cancer. For over a decade, there has been accumulating evidence that activated pancreatic stellate cells (PSCs) play a pivotal role in the development of pancreatic fibrosis in these pathological settings. In response to pancreatic injury or inflammation, quiescent PSCs undergo morphological and functional changes to become myofibroblast-like cells, which express $\alpha$-smooth muscle actin ( $\alpha$-SMA). Activated PSCs actively proliferate, migrate, produce extracellular matrix (ECM) components, such as type I collagen, and express cytokines and chemokines. In addition, PSCs might play roles in local immune functions and angiogenesis in the pancreas. Following the initiation of activation, if the inflammation and injury are sustained or repeated, PSCs activation is perpetuated, leading to the development of pancreatic fibrosis. From this point of view, pancreatic fibrosis can be defined as pathological changes of ECM composition in the pancreas both in quantity and quality, resulting from perpetuated activation of PSCs. Because the activation and cell functions in PSCs are regulated by the dynamic but coordinated activation of intracellular signaling pathways, identification of signaling molecules that play a crucial role in PSCs activation is important for the development of anti-fibrosis therapy. Recent studies have identified key mediators of stimulatory and inhibitory signals. Signaling molecules, such as peroxisome proliferator-activated receptor- $\gamma$ (PPAR- $\gamma$ ), Rho/Rho kinase, nuclear factor- $\kappa \mathrm{B}$
\end{abstract}

A. Masamune $(\square) \cdot$ T. Shimosegawa

Division of Gastroenterology,

Graduate School of Medicine, Tohoku University,

1-1 Seiryo-machi, Aoba-ku, Sendai 980-8574, Japan

e-mail: amasamune@int3.med.tohoku.ac.jp
(NF- $\kappa \mathrm{B})$, mitogen-activated protein (MAP) kinases, phosphatidylinositol 3 kinase (PI3K), Sma- and Mad-related proteins, and reactive oxygen species (ROS) might be candidates for the development of anti-fibrosis therapy targeting PSCs.

Keywords Pancreatic fibrosis - Pancreatitis . Pancreatic cancer · Myofibroblast · PPAR- $\gamma$

$\begin{array}{ll}\text { Abbreviations } \\ \text { AP-1 } & \text { Activator protein-1 } \\ \text { CP } & \text { Chronic pancreatitis } \\ \text { ECM } & \text { Extracellular matrix } \\ \text { ERK } & \text { Extracellular signal-regulated kinase } \\ \text { GFAP } & \text { Glial fibrillary acidic protein } \\ \text { HIF } & \text { Hypoxia-inducible factor } \\ \text { I } \kappa \text { B } & \text { Inhibitor of nuclear factor- } \kappa \text { B } \\ \text { IFN } & \text { Interferon } \\ \text { IL } & \text { Interleukin } \\ \text { JAK } & \text { Janus-activated kinases } \\ \text { JNK } & \text { c-Jun } N \text {-terminal kinase } \\ \text { MAP kinase } & \text { Mitogen-activated protein kinase } \\ \text { MCP-1 } & \text { Monocyte chemoattractant protein-1 } \\ \text { MMP } & \text { Matrix metalloproteinase } \\ \text { NADPH } & \text { Nicotinamide adenine dinucleotide } \\ & \text { phosphate } \\ \text { NF- } \kappa \text { B } & \text { Nuclear factor- } \kappa \text { B } \\ \text { PDGF } & \text { Platelet-derived growth factor } \\ \text { PI3K } & \text { Phosphatidylinositol } 3 \text { kinase } \\ \text { PPAR } & \text { Peroxisome proliferator-activated receptor } \\ \text { PSCs } & \text { Pancreatic stellate cells } \\ \text { ROS } & \text { Reactive oxygen species } \\ \text { SMA } & \text { Smooth muscle actin } \\ \text { Smad } & \text { Sma- and Mad }\end{array}$

Abbreviations

AP-1

$\mathrm{CP}$

Chronic pancreatitis

ECM

Extracellular matrix

ERK

Glial fibrillary acidic protein

GFAP

Hypoxia-inducible factor

$\mathrm{I} \kappa \mathrm{B}$

Inhibitor of nuclear factor- $\kappa \mathrm{B}$

IL

Janus-activated kinases

JNK

c-Jun $N$-terminal kinase

MAP kinase

MCP-1

Mitogen-activated protein kinase

MMP

Monocyte chemoattractant protein-1

Matrix metalloproteinase

phosphate

NF- $\kappa \mathrm{B} \quad$ Nuclear factor- $\kappa \mathrm{B}$

PDGF Platelet-derived growth factor

PI3K Phosphatidylinositol 3 kinase

PPAR Peroxisome proliferator-activated receptor

PSCs Pancreatic stellate cells

ROS Reactive oxygen species

Smad Sma- and Mad 
STAT Signal transducers and activators of transcription

TNF Tumor necrosis factor

TGF Transforming growth factor

TIMP Tissue inhibitor of metalloproteinase

TLR Toll-like receptor

VEGF Vascular endothelial growth factor WBN/Kob Wistar Bonn/Kobori

\section{Introduction}

Pancreatic fibrosis is a characteristic feature of chronic pancreatitis (CP) and of desmoplastic reaction associated with pancreatic cancer. Until recently, however, the molecular mechanisms of pancreatic fibrosis remained largely unknown at least in part because of the lack of in vitro models. In 1998, star-shaped cells in the pancreas, called pancreatic stellate cells (PSCs), were identified and characterized [1, 2]. For over a decade, there has been accumulating evidence that activated PSCs play a pivotal role in the development of pancreatic fibrosis in $\mathrm{CP}$ and in pancreatic cancer [1-8]. Because the activation and cell functions in PSCs are regulated by the dynamic but coordinated activation of intracellular signaling pathways, identification of signaling molecules that play a crucial role in PSCs activation is important for the development of antifibrosis therapy. In this review, we summarize the current knowledge about the PSCs biology, with a focus on the intracellular signaling pathways.

\section{Activation of PSCs}

In normal pancreas, stellate cells are quiescent and can be identified by the presence of vitamin A-containing lipid droplets in the cytoplasm [1-5]. Expression of the intermediate filament proteins desmin and glial fibrillary acidic protein (GFAP) is also used as a marker of quiescent PSCs. The expression and activation of GFAP has been confirmed in transgenic GFAP-LacZ mice where $2.2 \mathrm{~kb}$ of the GFAP promotor activity was associated exclusively with PSCs [9]. In response to pancreatic injury or inflammation, quiescent PSCs undergo morphological and functional changes to become myofibroblast-like cells, which express $\alpha$-smooth muscle actin ( $\alpha$-SMA). This step is called "activation." Activated PSCs lose lipid droplets, actively proliferate, migrate, and produce large amounts of extracellular matrix (ECM) components, such as type I collagen and fibronectin. In addition, activated PSCs acquire proinflammatory phenotypes; they express cytokines, chemokines, and cell adhesion molecule [3-6].
The critical regulatory events that induce PSCs activation in vivo are likely to be similar, at least in part, to the events that regulate the activation of primary PSCs in culture in vitro [1-8]. Studies of rat and human primary PSCs in culture have identified a variety of soluble factors, such as cytokines [interleukin (IL)-1, IL-6, and tumor necrosis factor (TNF)- $\alpha$ ] and growth factors [plateletderived growth factor (PDGF), transforming growth factor (TGF)- $\beta 1$, and activin $\mathrm{A}]$, ethanol and its metabolites, oxidative stress, and pressure, as well as extensive changes in the composition and organization of ECM, as regulators of PSCs activation (Fig. 1) [10-18]. Potential sources of these activating factors include activated macrophages, platelets, pancreatic acinar cells, and endothelial cells in inflamed pancreas. It has been shown that pancreatic cancer cells are also a source of PSC-activating factors [6-8]. The effects of IL- 1 and IL- 6 on the initiation of PSCs activation might be indirect, through the TGF- $\beta 1$ production [19]; anti-TGF- $\beta 1$ neutralizing antibody attenuated $\alpha$-SMA expression induced by IL-1 $\beta$ and IL-6 [19]. Importantly, PSCs by themselves are capable of synthesizing cytokines, such as TGF- $\beta 1$, activin A, and IL- 1 , suggesting the existence of autocrine loops that may contribute to the perpetuation of PSC activation after an initial exogenous signal, thereby promoting the development of pancreatic fibrosis [10-13].

Until now, the physiological consequence of vitamin A-storage in PSCs remains unclear. This vitamin A-storage might not only be a mere feature of quiescent PSC, but functionally contribute to the maintenance of this state.

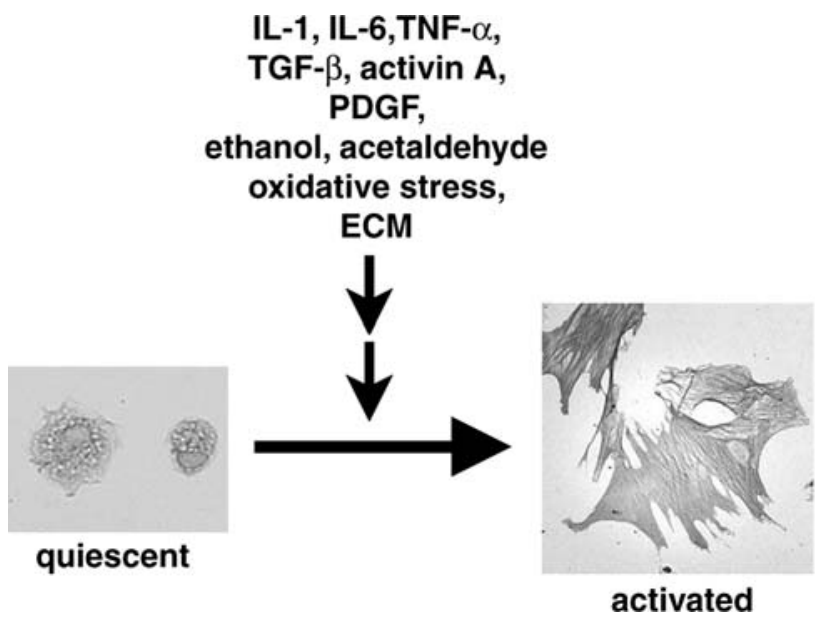

Fig. 1 Activation of quiescent PSCs. In response to pancreatic injury or inflammation, quiescent PSCs are transformed to myofibroblastlike cells. Studies of rat and human primary PSCs in culture have identified a variety of soluble factors, such as cytokines (IL-1, IL-6, TNF- $\alpha$ ) and growth factors (PDGF and TGF- $\beta 1$ ), ethanol and its metabolites, oxidative stress, pressure as well as extensive changes in the composition and organization of ECM, as regulators of PSCs activation 
McCarroll et al. [20] showed that retinol and its metabolites (all-trans retinoic acid and 9-retinoic acid) inhibited the induction of $\alpha$-SMA expression in PSCs. Retinol and its metabolites induced quiescence in culture-activated PSCs, in association with a significant decrease in the activation of mitogen-activated protein (MAP) kinases [20]. It is, therefore, tempting to speculate that retinoic acids are involved in the maintenance of a quiescent phenotype, through the binding to their nuclear receptors and the regulation of gene expression. In this scenario, the loss of retinoids in the course of PSCs activation might not be an epiphenomenon, but an essential prerequisite.

\section{Cell functions in PSCs}

Upon activation, PSCs actively proliferate, migrate, produce ECM components, and produce proinflammatory cytokines and chemokines. Cytokines and growth factors produced by acinar cells, inflammatory cells, platelets, endothelial cells, cancer cells, and PSCs by themselves would activate PSCs and induce these cell functions in paracrine and autocrine manners [1-8]. Although several inflammatory mediators released during the course of pancreatitis might regulate PSCs, accumulating evidence supports major roles for PDGF, which induces proliferation and migration of PSCs, and TGF- $\beta 1$, which induces PSCs to express $\alpha$-SMA and ECM proteins, as mediators of the persistently activated and profibrogenic phenotypes of these cells [10-13].

In addition to these well-known functions, recent studies have revealed that PSCs have a variety of cell functions (Table 1).

Not only producing ECM, PSCs also produce matrixdegrading enzymes of the matrix metalloproteinase (MMPs) family and their inhibitors [tissue inhibitors of metalloproteinases (TIMPs)] [21]. PSCs have been shown to secrete MMP-2, MMP-9, and MMP-13, and to express

Table 1 Cell functions in PSCs

$\alpha$-SMA expression

Proliferation

ECM production (type I, type III collagen, etc.)

Cytokine, chemokine production (IL-8, MCP-1, etc.)

Adhesion molecule (ICAM-1) expression

Migration/chemotaxis

Contractility

Matrix degradation (MMPs expression)

TLRs expression

Endocytosis and phagocytosis

Angiogenesis
TIMP-1 and TIMP-2 [21]. Thus, PSCs might be involved in the maintenance of normal tissue architecture by regulating ECM turnover. In this context, resolution of mouse cerulein-induced pancreatitis involves transient activation of PSCs and deposition of ECM proteins, as well as transient upregulation of MMPs and TIMPs [22]. On the other hand, MMP- 2 produced by PSCs might contribute to the progression of pancreatic cancer [23].

The increased expression of the cytoskeletal protein $\alpha$-SMA confers increased contractile potential, which is further increased by endothelin-1 [24]. Because PSCs are also located around the ductal and vascular structures [1-4], it would be of interest to see whether contraction of PSCs is involved in the regulation of vascular and ductal tones in the pancreas.

Pancreatic stellate cells have the ability to produce a wide variety of cytokines and growth factors. PSCs produce IL- $1 \beta$, IL- 6 , TNF- $\alpha$, TGF- $\beta 1$, and PDGF-BB, all of which contribute to the perpetuated activation of PSCs $[10-13,25]$. The ability of PSCs to produce IL-32, a cytokine mainly expressed by $\mathrm{T}$ lymphocytes, natural killer cells, monocytes, and epithelial cells, has been shown [26]. Chemokines [IL-8, monocyte chemoattractant protein (MCP)-1, and RANTES] produced by PSCs contributes to the recruitment of inflammatory cells to the inflamed pancreas [27]. Expression of cell adhesion molecules, such as intercellular adhesion molecule (ICAM)-1 in PSCs, also contributes to the adhesion of the inflammatory cells recruited [28]. Very recently, we and others have shown that PSCs expressed Toll-like receptors (TLRs), proteins involved in the activation of innate immunity [29, 30]. PSCs express TLR2, which recognizes pathogen-associated molecular patterns of gram-positive bacteria, and TLR4 recognizing lipopolysaccharides of gram-negative bacteria. PSCs also express TLR3, which recognizes double-stranded RNA produced during virus replication, and TLR5, which recognizes flagellin, the major portion of bacterial flagella. In addition, PSCs can perform endocytosis and phagocytosis of foreign bodies, necrotic debris, and aged polymorphonuclear cells, suggesting that PSCs might play a role in the immune functions locally in the pancreas [30, 31]. It is hence likely that PSCs play a "macrophage-like" role in the pancreas, comparable to the role of Kupffer cells in the liver. PSCs might contribute to regain organ homeostasis by engulfing pancreatic acinar cells undergoing apoptosis and necrosis.

Another novel function we recently identified in PSCs is related to angiogenesis [32]. PSCs constitutively produce vascular endothelial growth factor (VEGF), and the production is increased by hypoxia. In addition to VEGF, PSCs express several angiogenesis-regulating molecules, including VEGF receptors (Flt-1 and Flk-1), angiopoietin-1 and its receptor Tie-2, and vasohibin-1. Conditioned media 
of PSCs induced angiogenesis in vitro and in vivo; it increased tube formation on Matrigel and directed vessel formation in nude mice [32]. A significant association among fibrosis, angiogenesis, and higher VEGF expression has been reported in pancreatic cancer and in CP [33]. Thus, PSCs might play profibrogenic and proangiogenic roles during the development of pancreatic fibrosis, where they are subjected to hypoxia. Although further in vivo studies are needed for a more detailed characterization of this scenario, these findings suggest a novel mechanism linking hypoxia, inflammatory responses, angiogenesis, and fibrosis in the pancreas.

\section{Post-activation events}

Following the initiation of activation, PSCs have two fates (Fig. 2). If the inflammation and injury are sustained or repeated, PSC activation is perpetuated, leading to the development of pancreatic fibrosis. In contrast, if the inflammation and injury are controlled or single, PSCs might undergo apoptosis or reverse to quiescent stage. In this case, fibrosis will not be developed or even resolved. From this point of view, pancreatic fibrosis can be defined as pathological changes of ECM composition in the pancreas both in quantity and quality, resulting from perpetuated activation of PSCs. For the development of pancreatic fibrosis, repeated and persistent injury and inflammation are important. This is well in agreement with the concept that repeated episodes of acute pancreatitis attacks leads to the development of pancreatic fibrosis ("necrosis-fibrosis sequence") [34, 35].

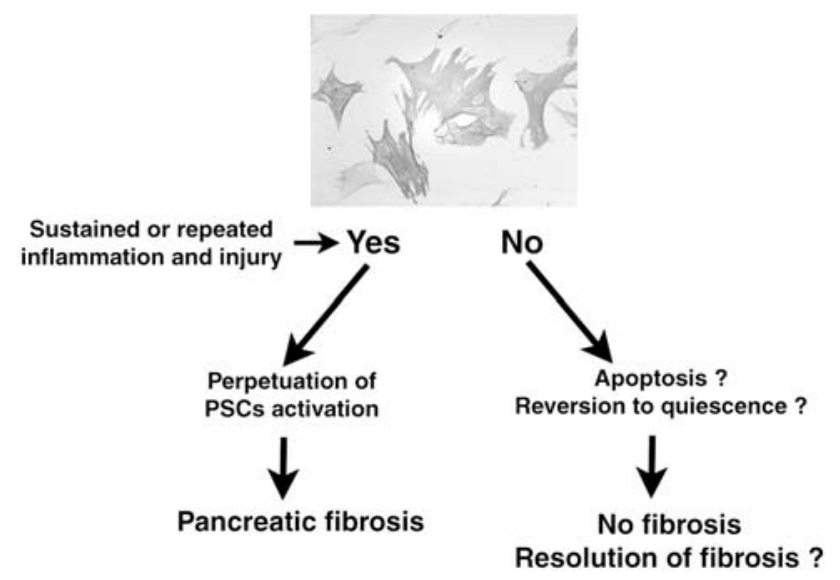

Fig. 2 Fate of activated PSCs. Following the initiation of activation, PSCs have two fates. If the inflammation and injury are sustained or repeated, PSCs activation is perpetuated, leading to the development of pancreatic fibrosis. In contrast, if the inflammation and injury are controlled or single, PSCs might undergo apoptosis or reverse to quiescent stage. In this case, fibrosis will not be developed or even resolved

\section{Signal transduction in PSCs}

It has been shown that multiple signaling pathways and molecules are involved in the activation and cell functions in PSCs (Table 2). During the process of activation, dynamic but orchestrated changes in the intracellular signaling occur. Identification of signaling molecules regulating activation and cell functions in PSCs will provide a promising approach for the development of anti-fibrotic and anti-inflammatory therapies, and has, therefore, become a focus of attention.

\section{PPAR- $\gamma$}

Peroxisome proliferator-activated receptor- $\gamma(\operatorname{PPAR}-\gamma)$ is a member of the PPAR subfamily of nuclear hormone receptors, originally characterized as the master regulator for the development of adipocytes [36]. PPAR- $\gamma$ forms heterodimers with retinoic acid $X$ receptors and binds to cognate DNA elements, called the PPAR-response elements, in the $5^{\prime}$-flanking region of the target genes. Ligands of PPAR- $\gamma$ include oxidative metabolites of polyunsaturated fatty acids, prostaglandins of the $\mathrm{J}$ series, such as 15-deoxy- $\Delta^{12,14}$-prostaglandin $\mathrm{J}_{2}$, and the thiazolidinedione class of antidiabetic drugs, such as troglitazone. In addition to well-established roles in adiopocyte differentiation, PPAR $-\gamma$ has been implicated in the control of cell proliferation, macrophage function, and immunity [36]. Because PSCs lose their adiopogenic properties upon activation, negative regulation of $\operatorname{PPAR}-\gamma$ signaling is likely to be associated with PSCs activation. Studies using PPAR- $\gamma$ ligands and overexpression of PPAR- $\gamma$ have implicated this pathway in the maintenance of PSCs quiescence $[37,38]$. PPAR $-\gamma$ ligands inhibited proliferation, MCP-1 production, collagen synthesis, and $\alpha$-SMA expression in PSCs [37]. Of note, troglitazone inhibited the development of pancreatic fibrosis in vivo in male Wistar Bonn/Kobori (WBN/Kob) rats, a model of spontaneous CP in rats [39], and in mice induced by repeated injections of cerulein [40]. The roles of other PPAR members (PPAR- $\alpha$ and PPAR- $\beta$ ) as well as of other adipogenic transcription factors (e.g., cyclic AMP responsive element binding protein, CCAAT/enhancer-binding proteins, and sterol regulatory element binding protein-1c) in the activation of PSCs remain to be explored [41].

\section{Rho/Rho kinase}

During the process of PSCs activation, stress fiber formation is increased, suggesting cytoskeletal reorganization is involved in this process [42]. The small GTP-binding protein Rho has emerged as an important regulator of the actin cytoskeleton and cell morphology through the 
Table 2 Signal transduction pathways and cell functions in PSCs

\begin{tabular}{|c|c|c|}
\hline Signaling pathways & Stimuli & Cell functions \\
\hline PPAR- $\gamma$ & PPAR- $\gamma$ ligands & Maintenance of quiescence \\
\hline \multirow[t]{2}{*}{ Rho/Rho kinase } & Culture on plastic & Regulation of actin cytoskeleton, contraction \\
\hline & Endothelin-1 & Regulation of actin cytoskeleton, contraction, migration \\
\hline \multirow[t]{4}{*}{$\mathrm{NF}-\kappa \mathrm{B}$} & Culture on plastic & Higher basal level of NF- $\kappa \mathrm{B}$ \\
\hline & IL-1, TNF- $\alpha$ & Cytokine (MCP-1, IL-6, IL-8) production, ICAM-1 expression \\
\hline & TLR ligands & Cytokine (MCP-1, IL-8) production, iNOS expression \\
\hline & Galectin-1 & Cytokine (MCP-1, IL-8) production \\
\hline \multirow[t]{4}{*}{ AP-1 } & $\mathrm{IL}-1 \beta, \mathrm{TNF}-\alpha$ & Cytokine (MCP-1, IL-6, IL-8) production \\
\hline & PDGF-BB & $?$ \\
\hline & Ethanol, acetaldehyde & $?$ \\
\hline & Hydrogen peroxide, HNE & $?$ \\
\hline \multirow[t]{12}{*}{ ERK } & IL-1, TNF- $\alpha$ & Cytokine (MCP-1, IL-6, IL-8), MMP-1 production \\
\hline & TLR ligands & Cytokine (MCP-1, IL-6, IL-8) production \\
\hline & PDGF & Proliferation \\
\hline & Pressure & Proliferation \\
\hline & Ethanol, acetaldehyde & $?$ \\
\hline & Hydrogen peroxide, HNE & Collagen production \\
\hline & Angiotensin-II & Proliferation \\
\hline & PDGF & Proliferation, TIMP-1 expression \\
\hline & Trypsin & Proliferation \\
\hline & Galectin-1 & Proliferation \\
\hline & TGF- $\beta$ & TGF- $\beta$ mRNA expression \\
\hline & Periostin & Periostin secretion, $\alpha$-SMA expression \\
\hline \multirow[t]{8}{*}{ p38 MAP kinase } & IL-1, TNF & Cytokine (MCP-1, IL-6, IL-8) production \\
\hline & Culture on plastic & Activation \\
\hline & Ethanol, acetaldehyde & Activation, collagen production \\
\hline & Pressure & Activation, collagen production \\
\hline & PDGF & Proliferation \\
\hline & Hydrogen peroxide, HNE & Collagen production \\
\hline & TLR ligands & Cytokine (MCP-1, IL-6, IL-8) production \\
\hline & High glucose & Collagen production \\
\hline \multirow[t]{5}{*}{ JNK } & PDGF & Proliferation \\
\hline & IL-1, TNF- $\alpha$ & Cytokine (MCP-1, IL-6, IL-8) production \\
\hline & Ethanol, acetaldehyde & $?$ \\
\hline & TLR ligands & Cytokine (MCP-1, IL-6, IL-8) production \\
\hline & Hydrogen peroxide, $\mathrm{HNE}$ & Collagen production \\
\hline \multirow[t]{3}{*}{ PI3 K/Akt } & PDGF & Migration \\
\hline & Periostin & Migration \\
\hline & IL-1, TNF- $\alpha$, IFN- $\gamma$ & IL-32 $\alpha$ expression \\
\hline Src-JAK2-STAT3 & PDGF & Proliferation \\
\hline STAT1 & IFN- $\gamma$ & Growth inhibition \\
\hline Smad2 & TGF- $\beta$ & Activation, $\alpha$-SMA expression \\
\hline $\operatorname{Smad} 2 / 3$ & TGF- $\beta$ & ECM synthesis \\
\hline Smad3 & TGF- $\beta$ & Growth inhibition, IL- $1 \beta$ secretion \\
\hline $\operatorname{Smad} 2 / 3$ & TGF- $\beta$ & COX-2 expression \\
\hline Smad7 & Angiotensin II & Blocking TGF- $\beta$-mediated growth inhibition \\
\hline HIF- $1 \alpha$ & Hypoxia & VEGF production \\
\hline
\end{tabular}


Table 2 continued

\begin{tabular}{lll}
\hline Signaling pathways & Stimuli & Cell functions \\
\hline Gli-1 & Sonic hedgehog & Activation, proliferation, migration \\
& IHH & Migration, MT1-MMP expression \\
\hline
\end{tabular}

HNE 4-Hydroxy-2,3-nonenal

downstream effector Rho kinase [43]. Roles of Rho/Rho kinase have been dissected using Y-27632 and HA-1077 (fasudil), specific inhibitors of Rho kinase. When activated PSCs were treated with Y-27632, cells changed to an elongated, fusiform morphology with prominent dendritic processes [42], suggesting that Rho kinase was necessary as a downstream effector of Rho for the cell spreading in PSCs. Concomitantly, Y-27632 caused disassembly of stress fibers. Y-27632 and HA-1077 inhibited spontaneous activation of freshly isolated PSCs in culture on plastic, suggesting that Rho-Rho kinase pathway plays a role in the activation process of PSCs by regulating the actin cytoskeleton. In addition, Y-27632 and HA-1077 inhibited $\alpha$ SMA expression, proliferation, chemotaxis, and type I collagen production in culture-activated PSCs. Y-27632 inhibited contraction and migration in response to endothelin-1 [24]. In this context, there is accumulating evidence that RhoA activation serves as a convergence point for multiple environmental factors known to regulate smooth muscle cell-specific gene expression and differentiation. For example, integrin-matrix interactions, mechanical stretch, and contractile agonists, such as endothelin-1 and angiotensin II, are known to regulate smooth muscle cell-specific gene expression including $\alpha$ SMA as well as the activity of RhoA [44].

\section{Nuclear factor- $\kappa \mathrm{B}(\mathrm{NF}-\kappa \mathrm{B})$}

Nuclear factor- $\kappa \mathrm{B}$ is composed of hetero- or homodimers of the Rel protein family (p65, p50, p52, c-Rel, and RelB), with the p65:p50 heterodimer being the classic NF- $\kappa \mathrm{B}$ complex induced by cytokine, mitogen, or ultraviolet stimulation of mammalian cells [45]. The level of cellular NF- $\kappa \mathrm{B}$ activity is determined by the properties of its naturally occurring inhibitors, of which inhibitor of nuclear factor $-\kappa \mathrm{B}(\mathrm{I} \kappa \mathrm{B}-\alpha)$ is the best characterized. Induction of $\mathrm{NF}-\kappa \mathrm{B}$ during PSCs activation is characterized by persistent elevation of NF- $\kappa \mathrm{B}$ activity relative to that observed in quiescent PSCs. As a result, activated PSCs express a variety of NF- $\kappa$ B responsive genes, including ICAM-1, that are not associated with the quiescent cells [28]. Precisely how the PSCs regulates this shift toward a higher basal level of NF- $\kappa$ B activity is unsolved, but is likely to be associated with a persistent reduction in the cytoplasmic and nuclear expression of $\mathrm{I} \kappa \mathrm{B}-\alpha$ [46]. NF- $\kappa \mathrm{B}$ activity can be further elevated in a transient manner following stimulation of PSCs with proinflammatory cytokines, which result in enhanced expression of NF- $\kappa \mathrm{B}$ responsive genes such as IL-6, IL-8, MCP-1, and ICAM-1 [25, 27, 28]. In addition, it has been shown that TLR ligands, such as lipoteichoic acid (a ligand for TLR2), polyinosinic-polycytidylic acid (a ligand for TLR3), lipopolysaccharide (a ligand for TLR4), and flagellin (a ligand for TLR5), activated NF- $\kappa$ B in PSCs [30]. All of the TLR ligands induced the expression of MCP-1, cytokine-induced neutrophil chemoattractant-1 (a rat homologue of IL-8), and inducible nitric oxide synthase, all of the production was abolished by Bay11-7082, a specific inhibitor of NF- $\kappa$ B [30]. Similarly, NF- $\kappa \mathrm{B}$ is activated by galectin- 1 , a member of the galectin family of $\beta$-galactoside-binding animal lectins, in PSCs [47]. Galectin-1-induced production of MCP-1 and cytokine-induced neutrophil chemoattractant-1 was abolished by Bay11-7082, suggesting a role of NF- $\kappa \mathrm{B}$ in galectin-1-induced cell functions.

\section{Activator protein-1 (AP-1)}

AP-1 is a transcription factor that plays roles in the regulation of different cellular processes, including cell proliferation, death, and inflammation [48, 49]. AP-1 is composed of Fos-Jun hetero- or Jun-Jun homodimers, which regulate transcription through the binding to specific AP-1 sites in the promoter region of target genes. Downstream of a variety of cytokine receptors, three wellcharacterized MAP kinase signal transduction pathways [extracellular signal-regulated kinase (ERK), c-Jun $N$-terminal kinase (JNK), and p38 MAP kinase] are involved in the regulation of AP-1-mediated gene expression [48, 49]. While the Ras-Raf-ERK pathway plays an essential role in the stimulation of fos gene expression by growth factors, the responses to proinflammatory cytokines mostly depend on the JNK pathway (mediating phosphorylation and activation of c-Jun) and the p38 MAP kinase pathway, which contributes to both fos and $c$-jun gene induction [48, 49]. As we will describe later, because activation of MAP kinases are involved in the activation of quiescent PSCs, it is likely that activation of AP-1 might also be involved in the process of activation. Fitzner et al. [50] examined the AP-1 activation during the activation process. They showed that maximal AP-1 activation was observed as 
early as 2 days after isolation, followed by a decrease of AP-1 DNA binding in older primary cultures. The presence of JunD in AP-1 complexes was typical for activated PSCs, while the portion of JunB-containing AP-1 complexes decreased during the course of activation, along with the overall decrease of AP-1 DNA binding activity [50]. Although these findings suggest distinct roles of individual Jun proteins in the regulation of PSCs functions, it remains unknown whether the activation (or deactivation) of AP-1 is required for the transformation to a myofibroblast-like phenotype at least in part due to the lack of specific AP-1 inhibitors.

However, the abilities of cytokines (IL- $1 \beta$ and TNF- $\alpha$ ), growth factors (PDGF-BB), ethanol and its metabolites, aldehydes, oxidative stresses, and trypsin to induce AP-1 activation have been shown in PSCs [28, 37, 51-55]. Again, because specific AP-1 inhibitors are not readily available, roles of AP-1 activation in PSCs remain largely unknown.

\section{MAP kinases}

One of the major signaling pathways by which a mammalian cell responds to extracellular stimuli is through the activation of MAP kinases. MAP kinases play a role in a variety of cellular processes, including cell proliferation, cell survival, apoptosis, and cytokine production [56]. Members of the MAP kinase family, ERK, JNK, and p38 MAP kinase, are central elements that transduce the signal generated by growth factors, cytokines, and stresses [56]. Each member of this kinase family is activated by phosphorylation and subsequently translocates into the cell nucleus. Once in the nucleus, it phosphorylates and activates transcription factors, such as AP- 1 and $\mathrm{NF}-\kappa \mathrm{B}$, ultimately resulting in the transcription of specific genes. In PSCs, it has been shown that a variety of stimuli, including proinflammatory cytokines, TLR ligands, angiotensin II, ethanol and its metabolites, aldehydes, oxidative stresses, and trypsin, activated these three classes of MAP kinases (ERK, JNK, and p38 MAP kinase) [28, 30, 37, 51-55, 57-60]. Mainly by experiments using pharmacological inhibitors, it has been shown that activation of MAP kinases play an important role in the production of cytokines and chemokines in PSCs [30, 57-59]. In addition, each member of MAP kinases differentially regulates the activation and cell functions in PSCs.

Extracellular signal-regulated kinase activation is an early event that precedes the increase of $\alpha$-SMA expression [54]. In many types of cells, a central role of the Ras-RafERK1/2 signal transduction pathway in the regulation of cell growth is well documented [56]. It has been shown that ERK mediates PSC proliferation in response to PDGF-BB, one of the most potent mitogens for PSCs in vitro [54, 59]. In addition, ERK mediates PSC proliferation in response to various stimuli, including angiotensin II, pressure, trypsin, and galectin-1 [16, 47, 55, 61]. Yoshida et al. [62] showed that conditioned media of pancreatic cancer cells increased proliferation and TIMP-1 expression through the activation of the ERK pathway. PDGF in the conditioned media might be responsible for these stimulatory actions [6-8]. Of note, angiotensin II stimulates PSCs proliferation by activating ERK through epidermal growth factor receptor transactivation; both PD98059 (an inhibitor of ERK pathway) and AG1478 (an inhibitor of epidermal growth factor receptor kinase inhibitor) attenuated ERK activation and DNA synthesis in PSCs [61]. Another PSCs function regulated by ERK is MMP-1 production. It has been shown that IL- $1 \beta$ and TNF- $\alpha$ induced MMP- 1 production through the activation of ERK, but not NF- $\kappa$ B or p38 MAP kinase [63].

There is accumulating evidence that p38 MAP kinase mediates the activation of quiescent PSCs [57]. Inhibitors of p38 MAP kinase inhibited the activation of PSCs in response to serum-containing medium in culture [57], pressure, ethanol, and acetaldehyde [64]. It has been shown that p38 MAP kinase regulates collagen production in response to ethanol, acetaldehyde, and oxidative stresses [51-53, 57]. In contrast, ethanol- and acetaldehyde-induced PSCs activation (as shown by increased $\alpha$-SMA expression) was not inhibited by inhibitors of ERK or JNK [64]. Although the contribution might be less evident than ERK pathway, p38 MAP kinase is involved in PDGF-induced PSCs proliferation [57].

Because SP600125, an inhibitor of JNK, failed to inhibit the transformation of quiescent PSCs [58], involvement of JNK in PSCs activation is less likely. Presumably, JNK is likely to be involved in the apoptosis induction in PSCs [65], a research area that remains largely unexplored.

\section{Phosphatidylinositol 3 kinase (PI3K)-Akt pathway}

Another major intracellular signaling pathway located downstream of PDGF receptor is PI3 K-Akt pathway. By using immunoprecipitation and kinase assays, we reported that PDGF-BB activated PI3K-Akt pathway in PSCs [59]. Activation of this pathway mediates PDGF-induced PSCs migration, but not proliferation [59, 66]. Activation of this pathway also mediates PSCs migration in response to periostin [67]. In contrast, endothelin-1-induced migration was not mediated by PI3K-Akt pathway, because endothelin-1-failed to activate this signaling pathway in PSCs [24]. Recently, it has been shown that IL- $1 \beta$, TNF- $\alpha$, and interferon (IFN) $-\gamma$ activated Akt, and that LY294002, an inhibitor of PI3K, inhibited IL-32 $\alpha$ expression in response to these stimuli [26]. Although the activation of PI3K was 
not directly presented, these findings suggest that the role of PI3K-Akt pathway is not restricted to cell migration.

Janus-activated kinases (JAK)/signal transducers and activators of transcription (STAT)

Janus-activated kinases are a group of non-receptor tyrosine kinases that, via phosphorylation, modulate the activities of a group of transcription factors, viz. STAT [68]. The STAT proteins exist in a latent form in the cytoplasm, and, upon receptor activation by cytokines and growth factors, become phosphorylated on tyrosine residues [68]. This phosphorylation results in translocation of the STATs to the nucleus, where they bind to sequencespecific DNA elements. In addition to ERK and PI3K-Akt pathways, it has been shown that PDGF-BB activated Src, JAK2, STAT1, and STAT3 in PSCs [69]. PDGF-induced activation of STAT1 and STAT3 was inhibited by a Src inhibitor PP1 and a JAK2 inhibitor AG490. PDGF-induced proliferation was inhibited by PP1 and AG490 as well as by STAT3 antisense oligonucleotide. Thus, Src-dependent activation of the JAK2-STAT3 pathway is involved in the PDGF-induced PSCs proliferation.

The abilities of IFN- $\beta$ and IFN- $\gamma$ to induce STAT1 and STAT3 activation have been reported in PSCs [70]. Inhibition of STAT1 expression by RNA interference was associated with a significantly reduced growth-inhibitory effect of IFN- $\gamma$, suggesting a direct involvement of STAT1 in growth inhibition by IFN- $\gamma$ [70].

Sma- and Mad-related proteins (Smads)

TGF- $\beta 1$ is known to be the critical regulator of pancreatic fibrosis. TGF- $\beta 1$ intracellular signaling is mediated and modulated primarily by Smads. Upon TGF- $\beta 1$-binding to its receptor, Smad 2 and Smad3 are phosphorylated by the receptor and form oligomeric complexes with Smad4; the complexes then translocate into the nucleus. These complexes subsequently activate the transcription of target genes. In addition to the Smad-dependent pathway, Smadindependent TGF- $\beta$ signaling pathways exist, for example, MAP kinases, such as ERK. Thus, TGF- $\beta 1$ intracellular signaling occurs via Smad-dependent and Smad-independent pathways [19].

TGF- $\beta 1$ regulates a variety of PSCs functions, including increased ECM synthesis, increased activation and $\alpha$-SMA expression, attenuated proliferation, and reduced expression of MMP-3 and MMP-9 [71]. Ohnishi et al. [72] examined the roles of Smads in TGF- $\beta 1$-mediated regulation of PSCs functions. They showed that Smad2, Smad3, and Smad4 were functionally active in PSCs. By using adenovirus-mediated gene transfer, they showed that dominant-negative Smad2/3 inhibited PSCs activation and enhanced their proliferation. Co-expression of Smad2 with dominant-negative $\mathrm{Smad} 2 / 3$ restored PSC activation inhibited by dominant-negative Smad2/3 expression without changing their proliferation. By contrast, co-expression of Smad3 with dominant-negative Smad2/3 attenuated PSC proliferation enhanced by dominant-negative $\operatorname{Smad} 2 / 3$ expression without altering their activation. Exogenous TGF- $\beta 1$ increased TGF- $\beta 1$ mRNA expression, which was inhibited by PD98059, an inhibitor of ERK pathway. Thus, TGF- $\beta 1$ differentially regulates PSCs activation, proliferation, and TGF- $\beta 1$ mRNA expression through Smad2-, Smad3-, and ERK-dependent pathways, respectively [72].

In addition, several interactions between Smads and other signaling pathways have been shown. Angiotensin II enhanced PSCs proliferation by blocking autocrine TGF- $\beta 1$-mediated growth inhibition by inducing Smad7 expression [73]. It has been proposed that an autocrine loop exists between TGF- $\beta 1$ and IL- $1 \beta$ through Smad3- and ERK-dependent pathways [74]. Another autocrine loop may exist between IL- 6 and TGF- $\beta 1$ through ERK- and Smad2/3-dependent pathways in activated PSCs [75]. Interestingly, it has been recently shown that cyclooxygenase- 2 expression, induced by TGF- $\beta 1$ through Smad2/ 3 -dependent pathways, is required for activated PSCs to respond to proinflammatory cytokines [19].

RECK is a novel membrane-anchored MMP inhibitor. It has been recently shown that TGF- $\beta$ signaling in activated PSCs may promote ECM accumulation via a mechanism that preserves the protease inhibitory activity of RECK [76]. Expression of RECK is regulated by the Smads system; Smad7 overexpression or suppression of Smad3 expression led to the loss of RECK protein expression [76].

\section{Hypoxia-inducible factor (HIF-1)}

A hypoxic environment in tumor plays an important role in pancreatic cancer progression, and $\mathrm{CP}$ is also characterized by hypoxia $[77,78]$. Recent studies have suggested that a hypoxic environment concomitantly exists not only in cancer cells, but also in surrounding PSCs [79]. Therefore, PSCs, cancer cells, endothelial cells, and other cells involved in the development of pancreatic fibrosis have to operate in coordination with a low-oxygen microenvironment. The cellular response to hypoxia is mediated by the transcription factor HIF-1, which is a heterodimer protein composed of $\alpha$ and $\beta$ subunits [80]. While HIF-1 $\beta$ protein is constitutively expressed under normoxia, HIF- $1 \alpha$ is unstable under normoxia due to an $\mathrm{O}_{2}$-dependent degradation involving an ubiqutin-proteasomal pathway. HIF- $1 \alpha$ is an $\mathrm{O}_{2}$-sensitive partner, as it is accumulated under hypoxia, translocates to the nucleus, and transactivates a variety of genes including VEGF and plasminogen activator inhibitor-1 [80]. Very recently, we have shown that 
hypoxia induced nuclear expression of HIF- $1 \alpha$, followed by the production of VEGF in PSCs [32]. HIF-1 $\alpha$ induction implies that PSCs might serve as oxygen-sensing cells in the pancreas.

\section{Sonic hedgehog-Gli-1}

Indian hedgehog (IHH) is a member of hedgehog peptide family that exerts diverse effects on multiple cellular functions mainly through the transcription factor Gli-1 [81]. Shinozaki et al. [82] examined the role of IHH in rat PSCs. They showed that activated PSCs express both patched-1 and smoothened, essential components of hedgehog receptor system. IHH enhanced PSC migration in both chemotactic and chemokinetic manners, whereas type I collagen expression, $\alpha$-SMA expression, or proliferation was not altered. Furthermore, IHH increased the expression of membrane-type $1 \mathrm{MMP}$ and altered its localization on the plasma membrane. IHH induced nuclear accumulation of Gli-1 in PSCs. Unexpectedly, however, adenovirusmediated Gli-1 overexpression blocked the PSCs migration and membrane-type 1 MMP localization on the plasma membrane. Furthermore, reduction of Gli-1 expression with RNA interference augmented IHH-stimulated PSC migration. These data indicate that IHH promotes PSC migration by enhancing the localization of membrane-type 1 MMP on the plasma membrane, but is negatively regulated by Gli-1 [82].

Very recently, Bailey et al. [83] reported that recombinant sonic hedgehog increased activation, proliferation, and migration in human PSCs. Although roles of Gli-1 were not examined in detail, it is likely that activation of the sonic hedgehog signaling plays a role in the activation and cell functions in PSCs, contributing to the development of tumor desmoplasia.

\section{Reactive oxygen species (ROS)}

A variety of signal transduction and gene expression systems, including AP-1, NF- $\kappa \mathrm{B}$, and MAP kinases, might be regulated by the intracellular generation of ROS. It has been shown that antioxidants including plant polyphenols inhibited the activation and cell functions in PSCs both in vitro and in vivo [15, 51, 84-91]. For example, ethanol- or acetaldehyde-induced collagen production was inhibited by antioxidants such as vitamin $\mathrm{E}$ and $\mathrm{N}$-acetly-cysteine [15, 51]. Green tea polyphenol epigallocatechin-3-gallate blocked PDGF-induced proliferation and migration in PSCs [84]. Similarly, epigallocatechin-3-gallate inhibited pressure-induced $\alpha$-SMA expression, type I collagen production, TGF- $\beta 1$ production, and transformation to a myofibroblast-like phenotype [85]. Other plant polyphenols, such as ellagic acid and curcumin, inhibited the proliferation, MCP-1 production, collagen expression, $\alpha$-SMA expression, and transformation to myofibroblastlike cells [86, 87]. Ellagic acid was shown to inhibit the development of pancreatic fibrosis in vivo in male WBN/ Kob rats [88]. DA-9601, a phytochemical possessing antiinflammatory and antioxidative action, inhibited the development of pancreatitis in mice after repeated injections of cerulein [89]. Very recently, we have shown that nicotinamide adenine dinucleotide phosphate (NADPH) oxidase might be a source of ROS in PSCs [90]. PSCs expressed key components of NADPH oxidase (p22 ${ }^{\text {phox }}$, $\mathrm{p} 47^{\text {phox }}$, NOX1, gp91 ${ }^{\text {phox }} / \mathrm{NOX} 2$, NOX4, and NOX activator 1). PDGF-BB, IL-1 $\beta$, and angiotensin II induced ROS production, which was abolished by diphenylene iodonium and apocynin, inhibitors of NADPH oxidase. Diphenylene iodonium inhibited PDGF-induced proliferation, IL-1 $\beta$-induced chemokine production, and expression of $\alpha$-SMA and collagen. Diphenylene iodonium inhibited transformation of freshly isolated cells to a myofibroblastlike phenotype. In addition, diphenylene iodonium inhibited the development of pancreatic fibrosis in WBN/Kob rats and in rats with dibutyltin dichloride-induced CP [90]. Because it is likely that ROSs mediate activation and cell functions, at least in part through the diverse regulation of intracellular signaling pathways, in PSCs, antioxidants might be candidates for the development of anti-fibrosis therapy targeting PSCs [91].

\section{Conclusive remarks}

As described above, studies on the regulation of activation and cell functions in PSCs at the intracellular level have identified key mediators of stimulatory and inhibitory signals. Signaling molecules, such as PPAR- $\gamma$, MAP kinases, PI3K, Smads, and ROS, might become an important target for the treatment of pancreatic fibrosis in the future. Importantly, we have to keep in mind that PSCs are morphologically and functionally very similar to hepatic stellate cells, the major effector cells in liver fibrosis. DNA array showed that only 29 out of 23,000 genes (only $0.1 \%$ ) were different between PSCs and hepatic stellate cells [92]. Therefore, research of PSCs should develop in directions more relevant to the pathophysiology of the pancreas, e.g., trypsin, non-oxidative alcohol metabolites, and pancreatic cancer.

Acknowledgments This work was supported in part by a grantin-aid from the Japan Society for the Promotion of Science (to A. Masamune), by the Pancreas Research Foundation of Japan (to A. Masamune), by the Kanae Foundation for Life and Socio-Medical Science (to A. Masamune), and by the Uehara Memorial Foundation (to A. Masamune). The authors are grateful to Drs. Kazuhiro Kikuta, Masahiro Satoh, Noriaki Suzuki, Takashi Watanabe, Yoshitaka Sakai, 
and Masayoshi Yoshida, who significantly contributed to research achievements in this field in our laboratory. We apologize for being unable to include all the references related to this field because of space limitation.

\section{References}

1. Apte MV, Haber PS, Applegate TL, Norton ID, McCaughan GW, Korsten MA, et al. Periacinar stellate-shaped cells in rat pancreas: identification, isolation and culture. Gut. 1998;43: 128-33.

2. Bachem MG, Schneider E, Gross H, Weidenbach H, Schmid RM, Menke A, et al. Identification, culture, and characterization of pancreas stellate cells in rats and humans. Gastroenterology. 1998;115:421-32.

3. Jaster R. Molecular regulation of pancreatic stellate cell function. Mol Cancer. 2004;3:26.

4. Pinzani M. Pancreatic stellate cells: new kids become mature. Gut. 2006;55:12-4.

5. Omary MB, Lugea A, Lowe AW, Pandol SJ. The pancreatic stellate cell: a star on the rise in pancreatic diseases. J Clin Invest. 2007;117:50-9.

6. Bachem MG, Schünemann M, Ramadani M, Siech M, Beger H, Buck A, et al. Pancreatic carcinoma cells induce fibrosis by stimulating proliferation and matrix synthesis of stellate cells. Gastroenterology. 2005;128:907-21.

7. Hwang RF, Moore T, Arumugam T, Ramachandran V, Amos $\mathrm{KD}$, Rivera A, et al. Cancer-associated stromal fibroblasts promote pancreatic tumor progression. Cancer Res. 2008;68:918-26.

8. Vonlaufen A, Joshi S, Qu C, Phillips PA, Xu Z, Parker NR, et al. Pancreatic stellate cells: partners in crime with pancreatic cancer cells. Cancer Res. 2008;68:2085-93.

9. Ding Z, Maubach G, Masamune A, Zhuo L. Glial fibrillary acidic protein promoter targets pancreatic stellate cells. Dig Liver Dis. 2009;41:229-36.

10. Apte MV, Haber PS, Darby SJ, Rodgers SC, McCaughan GW, Korsten MA, et al. Pancreatic stellate cells are activated by proinflammatory cytokines: implications for pancreatic fibrogenesis. Gut. 1999;44:534-41.

11. Luttenberger T, Schmid-Kotsas A, Menke A, Siech M, Beger H, Adler G, et al. Platelet-derived growth factors stimulate proliferation and extracellular matrix synthesis of pancreatic stellate cells: implications in pathogenesis of pancreas fibrosis. Lab Invest. 2000;80:47-55.

12. Schneider E, Schmid-Kotsas A, Zhao J, Weidenbach H, Schmid $\mathrm{RM}$, Menke A, et al. Identification of mediators stimulating proliferation and matrix synthesis of rat pancreatic stellate cells. Am J Physiol Cell Physiol. 2001;281:C532-43.

13. Mews P, Phillips P, Fahmy R, Korsten M, Pirola R, Wilson J, et al. Pancreatic stellate cells respond to inflammatory cytokines: potential role in chronic pancreatitis. Gut. 2002;50:535-41.

14. Ohnishi N, Miyata T, Ohnishi H, Yasuda H, Tamada K, Ueda N, et al. Activin A is an autocrine activator of rat pancreatic stellate cells: potential therapeutic role of follistatin for pancreatic fibrosis. Gut. 2003;52:1487-93.

15. Apte MV, Phillips PA, Fahmy RG, Darby SJ, Rodgers SC, McCaughan GW, et al. Does alcohol directly stimulate pancreatic fibrogenesis? Gastroenterology. 2000;118:780-94.

16. Watanabe S, Nagashio Y, Asaumi H, Nomiyama Y, Taguchi M, Tashiro M, et al. Pressure activates rat pancreatic stellate cells. Am J Physiol Gastrointest Liver Physiol. 2004;287: G1175-81.

17. Erkan M, Kleeff J, Gorbachevski A, Reiser C, Mitkus T, Esposito I, et al. Periostin creates a tumor-supportive microenvironment in the pancreas by sustaining fibrogenic stellate cell activity. Gastroenterology. 2007;132:1447-64.

18. Gao R, Brigstock DR. Connective tissue growth factor (CCN2) in rat pancreatic stellate cell function: integrin alpha5betal as a novel CCN2 receptor. Gastroenterology. 2005;129:1019-30.

19. Aoki H, Ohnishi H, Hama K, Shinozaki S, Kita H, Osawa H, et al. Cyclooxygenase- 2 is required for activated pancreatic stellate cells to respond to proinflammatory cytokines. Am J Physiol Cell Physiol. 2007;292:C259-68.

20. McCarroll JA, Phillips PA, Santucci N, Pirola RC, Wilson JS, Apte MV. Vitamin A inhibits pancreatic stellate cell activation: implications for treatment of pancreatic fibrosis. Gut. 2006; 55:79-89.

21. Phillips PA, McCarroll JA, Park S, Wu MJ, Pirola R, Korsten M, et al. Rat pancreatic stellate cells secrete matrix metalloproteinases: implications for extracellular matrix turnover. Gut. 2003; 52:275-82.

22. Lugea A, Nan L, French SW, Bezerra JA, Gukovskaya AS, Pandol SJ. Pancreas recovery following cerulein-induced pancreatitis is impaired in plasminogen-deficient mice. Gastroenterology. 2006;131:885-99.

23. Schneiderhan W, Diaz F, Fundel M, Zhou S, Siech M, Hasel C, et al. Pancreatic stellate cells are an important source of MMP-2 in human pancreatic cancer and accelerate tumor progression in a murine xenograft model and CAM assay. J Cell Sci. 2007; 120:512-9.

24. Masamune A, Satoh M, Kikuta K, Suzuki N, Shimosegawa T. Endothelin-1 stimulates contraction and migration of rat pancreatic stellate cells. World J Gastroenterol. 2005;11:6144-51.

25. Shimada M, Andoh A, Hata K, Tasaki K, Araki Y, Fujiyama Y, et al. IL-6 secretion by human pancreatic periacinar myofibroblasts in response to inflammatory mediators. J Immunol. 2002; 168:861-8.

26. Nishida A, Andoh A, Shioya M, Kim-Mitsuyama S, Takayanagi A, Fujiyama Y. Phosphatidylinositol 3-kinase/Akt signaling mediates interleukin-32alpha induction in human pancreatic periacinar myofibroblasts. Am J Physiol Gastrointest Liver Physiol. 2008;294:G831-8.

27. Andoh A, Takaya H, Saotome T, Shimada M, Hata K, Araki Y, et al. Cytokine regulation of chemokine (IL-8, MCP-1, and RANTES) gene expression in human pancreatic periacinar myofibroblasts. Gastroenterology. 2000;119:211-9.

28. Masamune A, Sakai Y, Kikuta K, Satoh M, Satoh A, Shimosegawa T. Activated rat pancreatic stellate cells express intercellular adhesion molecule-1 (ICAM-1) in vitro. Pancreas. 2002;25:78-85.

29. Vonlaufen A, Xu Z, Daniel B, Kumar RK, Pirola R, Wilson J, et al. Bacterial endotoxin: a trigger factor for alcoholic pancreatitis? Evidence from a novel, physiologically relevant animal model. Gastroenterology. 2007;133:1293-303.

30. Masamune A, Kikuta K, Watanabe T, Satoh K, Satoh A, Shimosegawa T. Pancreatic stellate cells express toll-like receptors. J Gastroenterol. 2008;43:352-62.

31. Shimizu K, Kobayashi M, Tahara J, Shiratori K. Cytokines and peroxisome proliferator-activated receptor gamma ligand regulate phagocytosis by pancreatic stellate cells. Gastroenterology. 2005;128:2105-18.

32. Masamune A, Kikuta K, Watanabe T, Satoh K, Hirota M, Shimosegawa T. Hypoxia stimulates pancreatic stellate cells to induce fibrosis and angiogenesis in pancreatic cancer. Am J Physiol Gastrointest Liver Physiol. 2008;295:G709-17.

33. Kuehn R, Lelkes PI, Bloechle C, Niendorf A, Izbicki JR. Angiogenesis, angiogenic growth factors, and cell adhesion molecules are upregulated in chronic pancreatic diseases: angiogenesis in chronic pancreatitis and in pancreatic cancer. Pancreas. 1999;18:96-103. 
34. Comfort H, Gambill E, Baggenstoss A. Chronic relapsing pancreatitis: a study of 29 cases without associated disease of the biliary or gastrointestinal tract. Gastroenterology. 1946;6:239-85.

35. Klöppel G, Maillet B. The morphological basis for the evolution of acute pancreatitis into chronic pancreatitis. Virchows Arch A Pathol Anat Histopathol. 1992;420:1-4.

36. Tontonoz P, Spiegelman BM. Fat and beyond: the diverse biology of PPARgamma. Annu Rev Biochem. 2008;77:289-312.

37. Masamune A, Kikuta K, Satoh M, Sakai Y, Satoh A, Shimosegawa $\mathrm{T}$. Ligands of peroxisome proliferator-activated receptor-gamma block activation of pancreatic stellate cells. J Biol Chem. 2002;277:141-7.

38. Jaster R, Lichte P, Fitzner B, Brock P, Glass A, Karopka T, et al. Peroxisome proliferator-activated receptor gamma overexpression inhibits pro-fibrogenic activities of immortalised rat pancreatic stellate cells. J Cell Mol Med. 2005;9:670-82.

39. Shimizu K, Shiratori K, Hayashi N, Kobayashi M, Fujiwara T, Horikoshi $\mathrm{H}$. Thiazolidinedione derivatives as novel therapeutic agents to prevent the development of chronic pancreatitis. Pancreas. 2002;24:184-90.

40. van Westerloo DJ, Florquin S, de Boer AM, Daalhuisen J, de Vos $\mathrm{AF}$, Bruno MJ, et al. Therapeutic effects of troglitazone in experimental chronic pancreatitis in mice. Am J Pathol. 2005; 166:721-8.

41. Tsukamoto H, She H, Hazra S, Cheng J, Miyahara T. Anti-adipogenic regulation underlies hepatic stellate cell transdifferentiation. J Gastroenterol Hepatol. 2006;21:S102-5.

42. Masamune A, Kikuta K, Satoh M, Satoh K, Shimosegawa T. Rho kinase inhibitors block activation of pancreatic stellate cells. Br J Pharmacol. 2003; 140:1292-302.

43. Takai Y, Sasaki T, Tanaka K, Nakanishi H. Rho as a regulator of the cytoskeleton. Trends Biochem Sci. 1995;20:227-31.

44. Yamakawa T, Yamakawa T, Tanaka S, Numaguchi K, Yamakawa Y, Motley ED, et al. Involvement of Rho-kinase in angiotensin II-induced hypertrophy of rat vascular smooth muscle cells. Hypertension. 2000;35:313-8.

45. Hayden MS, West AP, Ghosh S. NF-kappaB and the immune response. Oncogene. 2006;25:6758-80.

46. Elsharkawy AM, Wright MC, Hay RT, Arthur MJ, Hughes T, Bahr MJ, et al. Persistent activation of nuclear factor-kappa B in cultured rat hepatic stellate cells involves the induction of potentially novel Rel-like factors and prolonged changes in the expression of IkB family proteins. Hepatology. 1999;30:761-9.

47. Masamune A, Satoh M, Hirabayashi J, Kasai K, Satoh K, Shimosegawa T. Galectin-1 induces chemokine production and proliferation in pancreatic stellate cells. Am J Physiol Gastrointest Liver Physiol. 2006;290:G729-36.

48. Karin M, Liu ZG, Zandi E. AP-1 function and regulation. Curr Opin Cell Biol. 1997;9:240-6.

49. Shaulian E, Karin M. AP-1 in cell proliferation and survival. Oncogene. 2001;20:2390-400.

50. Fitzner B, Sparmann G, Emmrich J, Liebe S, Jaster R. Involvement of AP-1 proteins in pancreatic stellate cell activation in vitro. Int J Colorectal Dis. 2004;19:414-20.

51. Masamune A, Kikuta K, Satoh M, Satoh A, Shimosegawa T. Alcohol activates activator protein-1 and mitogen-activated protein kinases in rat pancreatic stellate cells. J Pharmacol Exp Ther. 2002;302:36-42.

52. Kikuta K, Masamune A, Satoh M, Suzuki N, Satoh K, Shimosegawa T. Hydrogen peroxide activates activator protein-1 and mitogen-activated protein kinases in pancreatic stellate cells. Mol Cell Biochem. 2006;291:11-20.

53. Kikuta K, Masamune A, Satoh M, Suzuki N, Shimosegawa T. 4-hydroxy-2, 3-nonenal activates activator protein-1 and mitogen-activated protein kinases in rat pancreatic stellate cells. World J Gastroenterol. 2004;10:2344-51.
54. Jaster R, Sparmann G, Emmrich J, Liebe S. Extracellular signal regulated kinases are key mediators of mitogenic signals in rat pancreatic stellate cells. Gut. 2002;51:579-84.

55. Masamune A, Kikuta K, Satoh M, Suzuki N, Shimosegawa T. Protease-activated receptor-2-mediated proliferation and collagen production of rat pancreatic stellate cells. J Pharmacol Exp Ther. 2005;312:651-8.

56. Chang L, Karin M. Mammalian MAP kinase signalling cascades. Nature. 2001;410:37-40.

57. Masamune A, Satoh M, Kikuta K, Sakai Y, Satoh A, Shimosegawa $\mathrm{T}$. Inhibition of p38 mitogen-activated protein kinase blocks activation of rat pancreatic stellate cells. J Pharmacol Exp Ther. 2003;304:8-14.

58. Masamune A, Kikuta K, Suzuki N, Satoh M, Satoh K, Shimosegawa T. A c-Jun N-terminal kinase inhibitor SP600125 blocks activation of pancreatic stellate cells. J Pharmacol Exp Ther. 2004;310:520-7.

59. Masamune A, Kikuta K, Satoh M, Kume K, Shimosegawa T. Differential roles of signaling pathways for proliferation and migration of rat pancreatic stellate cells. Tohoku J Exp Med. 2003;199:69-84.

60. Reinehr R, Zoller S, Klonowski-Stumpe H, Kordes C, Häussinger D. Effects of angiotensin II on rat pancreatic stellate cells. Pancreas. 2004;28:129-37.

61. Hama K, Ohnishi H, Yasuda H, Ueda N, Mashima H, Satoh Y, et al. Angiotensin II stimulates DNA synthesis of rat pancreatic stellate cells by activating ERK through EGF receptor transactivation. Biochem Biophys Res Commun. 2004; 315:905-11.

62. Yoshida S, Yokota T, Ujiki M, Ding XZ, Pelham C, Adrian TE, et al. Pancreatic cancer stimulates pancreatic stellate cell proliferation and TIMP-1 production through the MAP kinase pathway. Biochem Biophys Res Commun. 2004;323:1241-5.

63. Tasaki K, Shintani Y, Saotome T, Andoh A, Fujiyama Y, Hozawa S, et al. Pro-inflammatory cytokine-induced matrix metalloproteinase-1 (MMP-1) secretion in human pancreatic periacinar myofibroblasts. Pancreatology. 2003;3:414-21.

64. McCarroll JA, Phillips PA, Park S, Doherty E, Pirola RC, Wilson JS, et al. Pancreatic stellate cell activation by ethanol and acetaldehyde: is it mediated by the mitogen-activated protein kinase signaling pathway? Pancreas. 2003;27:150-60.

65. Dhanasekaran DN, Reddy EP. JNK signaling in apoptosis. Oncogene. 2008;27:6245-51.

66. McCarroll JA, Phillips PA, Kumar RK, Park S, Pirola RC, Wilson JS, et al. Pancreatic stellate cell migration: role of the phosphatidylinositol 3-kinase (PI3-kinase) pathway. Biochem Pharmacol. 2004;67:1215-25.

67. Erkan M, Kleeff J, Gorbachevski A, Reiser C, Mitkus T, Esposito $\mathrm{I}$, et al. Periostin creates a tumor-supportive microenvironment in the pancreas by sustaining fibrogenic stellate cell activity. Gastroenterology. 2007;132:1447-64.

68. Silva CM. Role of STATs as downstream signal transducers in Src family kinase-mediated tumorigenesis. Oncogene. 2004;23: 8017-23.

69. Masamune A, Satoh M, Kikuta K, Suzuki N, Shimosegawa T. Activation of JAK-STAT pathway is required for platelet-derived growth factor-induced proliferation of pancreatic stellate cells. World J Gastroenterol. 2005;11:3385-91.

70. Baumert JT, Sparmann G, Emmrich J, Liebe S, Jaster R. Inhibitory effects of interferons on pancreatic stellate cell activation. World J Gastroenterol. 2006;12:896-901.

71. Shek FW, Benyon RC, Walker FM, McCrudden PR, Pender SL, Williams EJ, et al. Expression of transforming growth factor-beta 1 by pancreatic stellate cells and its implications for matrix secretion and turnover in chronic pancreatitis. Am J Pathol. 2002;160:1787-98. 
72. Ohnishi H, Miyata T, Yasuda H, Satoh Y, Hanatsuka K, Kita H, et al. Distinct roles of Smad2-, Smad3-, and ERK-dependent pathways in transforming growth factor-beta1 regulation of pancreatic stellate cellular functions. J Biol Chem. 2004;279: 9973-8.

73. Hama K, Ohnishi H, Aoki H, Kita H, Yamamoto H, Osawa H, et al. Angiotensin II promotes the proliferation of activated pancreatic stellate cells by Smad7 induction through a protein kinase C pathway. Biochem Biophys Res Commun. 2006;340: 742-50.

74. Aoki H, Ohnishi H, Hama K, Ishijima T, Satoh Y, Hanatsuka K, et al. Autocrine loop between TGF-betal and IL-1beta through Smad3- and ERK-dependent pathways in rat pancreatic stellate cells. Am J Physiol Cell Physiol. 2006;290:C1100-8.

75. Aoki H, Ohnishi H, Hama K, Shinozaki S, Kita H, Yamamoto H, et al. Existence of autocrine loop between interleukin- 6 and transforming growth factor-betal in activated rat pancreatic stellate cells. J Cell Biochem. 2006;99:221-8.

76. Lee H, Lim C, Lee J, Kim N, Bang S, Lee H, et al. TGF-beta signaling preserves RECK expression in activated pancreatic stellate cells. J Cell Biochem. 2008;104:1065-74.

77. Koong AC, Mehta VK, Le QT, Fisher GA, Terris DJ, Brown JM, et al. Pancreatic tumors show high levels of hypoxia. Int J Radiat Oncol Biol Phys. 2000;48:919-22.

78. Patel AG, Toyama MT, Alvarez C, Nguyen TN, Reber PU, Ashley SW, et al. Pancreatic interstitial $\mathrm{pH}$ in human and feline chronic pancreatitis. Gastroenterology. 1995;109:1639-45.

79. Ide T, Kitajima Y, Miyoshi A, Ohtsuka T, Mitsuno M, Ohtaka K, et al. Tumor-stromal cell interaction under hypoxia increases the invasiveness of pancreatic cancer cells through the hepatocyte growth factor/c-Met pathway. Int J Cancer. 2006;119:2750-9.

80. Semenza GL. HIF-1: mediator of physiological and pathophysiological responses to hypoxia. J Appl Physiol. 2000;88:1474-80.

81. Nybakken K, Perrimon N. Hedgehog signal transduction: Recent findings. Curr Opin Genet Dev. 2002;12:503-11.

82. Shinozaki S, Ohnishi H, Hama K, Kita H, Yamamoto H, Osawa $\mathrm{H}$, et al. Indian hedgehog promotes the migration of rat activated pancreatic stellate cells by increasing membrane type- 1 matrix metalloproteinase on the plasma membrane. J Cell Physiol. 2008;216:38-46.

83. Bailey JM, Swanson BJ, Hamada T, Eggers JP, Singh PK, Caffery T, et al. Sonic hedgehog promotes desmoplasia in pancreatic cancer. Clin Cancer Res. 2008;14:5995-6004.

84. Masamune A, Kikuta K, Satoh M, Suzuki N, Shimosegawa T. Green tea polyphenol epigallocatechin-3-gallate blocks PDGFinduced proliferation and migration of rat pancreatic stellate cells. World J Gastroenterol. 2005;11:3368-74.

85. Asaumi H, Watanabe S, Taguchi M, Tashiro M, Otsuki M. Externally applied pressure activates pancreatic stellate cells through the generation of intracellular reactive oxygen species. Am J Physiol Gastrointest Liver Physiol. 2007;293:G972-8.

86. Masamune A, Satoh M, Kikuta K, Suzuki N, Satoh K, Shimosegawa T. Ellagic acid blocks activation of pancreatic stellate cells. Biochem Pharmacol. 2005;70:869-78.

87. Masamune A, Suzuki N, Kikuta K, Satoh M, Satoh K, Shimosegawa T. Curcumin blocks activation of pancreatic stellate cells. J Cell Biochem. 2006;97:1080-93.

88. Suzuki N, Masamune A, Kikuta K, Watanabe T, Satoh K, Shimosegawa T. Ellagic acid inhibits pancreatic fibrosis in male Wistar Bonn/Kobori rats. Dig Dis Sci. 2009;54:802-10.

89. Yoo BM, Oh TY, Kim YB, Yeo M, Lee JS, Surh YJ, et al. Novel antioxidant ameliorates the fibrosis and inflammation of ceruleininduced chronic pancreatitis in a mouse model. Pancreatology. 2005;5:165-76.

90. Masamune A, Watanabe T, Kikuta K, Satoh K, Shimosegawa T. NADPH oxidase plays a crucial role in the activation of pancreatic stellate cells. Am J Physiol Gastrointest Liver Physiol. 2008;294:G99-108.

91. Talukdar R, Tandon RK. Pancreatic stellate cells: new target in the treatment of chronic pancreatitis. J Gastroenterol Hepatol. 2008;23:34-41.

92. Buchholz M, Kestler HA, Holzmann K, Ellenrieder V, Schneiderhan W, Siech M, et al. Transcriptome analysis of human hepatic and pancreatic stellate cells: organ-specific variations of a common transcriptional phenotype. J Mol Med. 2005;83:795-805. 